\title{
PLAYING WITH FIRE, COMPETING WITH SPIRIT: COOPERATION IN THE SPORT OF ULTIMATE
}

\author{
Blaine G. Robbins \\ Department of Sociology, University of Washington, Seattle, \\ Washington, USA
}

Prior research shows that third-party agents are necessary to promote cooperation when groups are large and spatially diffuse. I explore whether this proposition holds in the self-governing sport of Ultimate. While the size of the community and spatial diffusion of the sport theoretically suggests limited decentralized control, the widespread implementation of a refereed system has not yet emerged. Instead, I find with qualitative methods that cooperation in Ultimate is the result of the sport being federally controlled and embedded within tiers of organizational constraint that promote informal regulation of competitions through norms, reputations, and self-discipline.

\section{INTRODUCTION}

Cooperation is considered a fundamental element of social order, and, along with social conflict and change, a classic focus of inquiry in sociology (Durkheim [1893]1984; Hobbes [1651]1968; Weber 1978). Examples of cooperation can be found in all walks of life, ranging from the political-European Union recognizing treaties - and the religious - the Amish erecting churches - to the criminal — street gangs controlling turf. However, the study of cooperation garners attention not just due to its prevalence but also due to its expected infrequency in the face of ubiquitous collective action problems and social dilemmas (Olson 1965). ${ }^{1}$ This is of particular interest because, theoretically, individuals should not cooperate, or act on collective interests and contribute to group endeavors, when it is in their individual interests to make use of a common good without having to contribute to its production or maintenance. Yet, empirically, cooperation and the alignment of collective interests with individual interests is a frequent social phenomenon.

To account for the observed collective action, social scientists have proposed two solutions. The first argues that cooperation can emerge spontaneously among

${ }^{1}$ I use social dilemma and collective action problem interchangeably.

I thank Heather Evans, Maria Grigoryeva, Gary Hamilton, Edgar Kiser, James Kitts, Karl-Dieter Opp, Steven Pfaff, Katherine Stovel, Michael Taylor, and Jacob Young for helpful comments on earlier versions of this article. I gratefully acknowledge the Ultimate community for making this project possible and the Mallards for not only providing a compelling case to study, but for years of fellowship and camaraderie.

Address correspondence to Blaine G. Robbins, Department of Sociology, University of Washington, 211 Savery Hall, Box 353340, Seattle, WA 98195-3340, USA. E-mail: adduct@u.washington.edu 
social actors without outside or top-down interventions (Axelrod 1984; Taylor 1976). Although this decentralized solution is effective under certain circumstances, it is usually observed that as groups increase in size or spatial distance the possibility of spontaneous cooperation precipitously declines (Bendor and Mookherjee 1987; Dixit 2004). This degeneration of cooperation due to group size or diffusion often justifies the necessity of the second, or centralized, solution. According to this explanation, groups that are at risk or succumb to social dilemmas will create agents that absorb monitoring costs and assign sanctions to opportunists in order to encourage social order (Hobbes [1651]1968; North 1990; Williamson 1985).

But is it always the case that spontaneous cooperation will fail under the pre-specified conditions? While groups do succumb to size and diffusion effects, clearly examples exist where groups successfully inhibit social conflict when the theoretical conditions are significantly weighed against them. This knowledge, however, is generally restricted to stylized simulations (e.g., Oliver and Marwell 1988), ethnographic studies of geographically proximal communities (see Ellickson 1991; Jimerson 1996; McLaughlin 2008), and experiments (e.g., Ostrom et al. 1992). Although the body of work reveals much about collective action and cooperation, there are very few empirical cases of groups that have successfully resolved the size and spatial distance effects without resorting to hierarchical control. Thus, lending support to the centralized solution.

In this article, I describe the organizational and institutional structure of a large and spatially dispersed self-governed sporting community known as Ultimate. I show that this community overcomes the problem of group size and geographic distance during competition not by a third-party agent - as centralists theoretically expect - but by relying partially on organizational control and almost exclusively on a concatenation of informal social control mechanisms such as norms, reputations, and self-discipline; illustrating that the scope of decentralized control can be extended beyond its theoretically expected bounds with the help of a federated system (Simon 1969). ${ }^{2}$ The goals of this article are twofold: (1) to empirically contribute to a theoretical problem; and (2) to better understand the control capacity of private-decentralized social control.

The roadmap of the article is as follows. I begin by outlining the theoretical problem and provide a brief review of salient existing literature on social dilemmas and cooperation. Because Ultimate is a relatively unknown case, I describe the sport, its governing bodies, and the ethos known to all players. Next, I describe the various methods and data sources and examine the collective action problem facing the Ultimate community. I then introduce the private-decentralized and centralized mechanisms of control and show that while the governing bodies manage costly forms of malfeasance, they play a limited role in promoting cooperative competition. Instead, what accounts for this cooperation is a concatenation of private-decentralized institutions and informal social control mechanisms. Lastly, I discuss the findings and provide a conclusion.

\footnotetext{
${ }^{2}$ I define federated structures of control as nested units (or groups) within units; or, more specifically, as self-governing units (or groups) nested within a centralized organization of governance.
} 


\section{THEORY OF COOPERATION, GROUP SIZE, AND SPATIAL DIFFUSION}

Two principle perspectives, the decentralized and centralized, have been used to account for why people cooperate when it is not in their interests to contribute to collective endeavors (i.e., free-ride). Decentralized theories, on the one hand, explain cooperation as a product of spontaneous interaction that can occur even amongst the most self-regarding actors. Centralized theories, on the other hand, explain cooperation in terms of a set of institutional and organizational properties, such as third-party agents, that monitor and sanction group members.

According to the decentralized perspective, it is possible to sustain cooperation without third-party control when two actors are stuck in a prisoner's dilemma, or a situation where it is collectively most beneficial for both actors to cooperate but individually more beneficial for both actors to cheat (Axelrod 1984; Bendor and Mookherjee 1987; Hardin 1982). Taylor (1976) formally discovered that if actors do not heavily discount future rewards, and repeated interaction is indefinite, there is potential for spontaneous cooperation. The idea is that with infinite social interaction the long-term gains of cooperation outweigh the short-term gains of malfeasance and a strategy of conditional cooperation becomes possible, directing individuals to reciprocate cooperation with cooperation and opportunism with opportunism.

Although decentralists show how spontaneous cooperation is possible, the scope of the solution is constrained by two parameters: group size and spatial distance. Scholarly work suggests that spontaneous cooperation precipitously declines as group size increases (Kollock 1998). Bendor and Mookherjee (1987) found with simulations that group size is deleterious for social order because it is more difficult for actors to observe all behavior and sanction malfeasance under such conditions. Experimental studies confirm this and show that anonymity, which accompanies large groups dispersed over vast geographic areas, drastically lowers rates of cooperation (see Fox and Guyer 1978; Jerdee and Rosen 1974). ${ }^{3}$ Thus, with these effects, a number of correlated problems emerge: coordination and communication declines, the effectiveness of individual reputations weaken, and monitoring and sanctioning mechanisms lose hold. As result, individual investment in the provision of common goals precipitously falls (see Dixit 2004). The outcome is either the dissolution of the group or the creation of a third-party agent that detects malfeasance, enforces rules, and ensures cooperation (North 1990; Williamson 1985).

This observation is further supported by the fact that very few ethnographic cases exist where large and spatially diffuse groups cooperate without centralized control. Table 1 illustrates the literature thus far. Given a simplified depiction of group size (small versus large) and spatial distance (proximate versus distal), the empirical work supporting the decentralized thesis falls within cells 1 through 3 . In cell 1 , monitoring and sanctioning capacity is robust and information exchange is efficient because the group is small and geographically proximal, thus facilitating the effectiveness of informal social control (Hechter 1987). Kanter's (1972) work on

\footnotetext{
${ }^{3}$ Defining "group size" in relation to social dilemmas is a difficult task. The experiments cited here suggest that groups as small as 3 members will produce lower rates of cooperation, while social simulations show that cooperation in groups as large as 1,500 will collapse without centralized third-party agents. What is important, however, is that the Ultimate community is much larger than the decentralized bounds set by either experiments or simulations.
} 
Table 1 Theoretical group dimensions

\begin{tabular}{lcc}
\hline & Spatially proximal & Spatially diffuse \\
\hline Small Groups & Cell 1 & Cell 2 \\
& Kanter 1972 & Ellickson 1988 \\
Large Groups & Cell 3 & Cell 4 \\
& Ostrom 1990 & $?$ \\
\hline
\end{tabular}

commitment in American communes, for instance, falls within this cell (see Geertz 1978 for a classic example). Groups found in cells 2 and 3 often suffer reductions in information exchange and weakened monitoring and sanctioning capacity as a result of the group size or spatial diffusion effects. Decentralized and centralized solutions have been found to exist within both of these cells. Ellickson's (1989) whale hunters and Ostrom's (1990) CPRs are appropriately located in cells 2 and 3 (see Greif 1989; Landa 1981 as well). Cell 4, however, has yielded very little empirical work showing large and geographically diffuse groups cooperating only with decentralized control mechanisms, which poses the theoretical problem: Are decentralized solutions impossible under conditions found in cell 4 ?

Addressing the empirical gap indicated by Cell 4 is a key component of this article, and it does so by shedding light on the case of Ultimate: a self-refereed sport spread across the world that, since 1968, is experiencing rapid organizational membership growth while concurrently reproducing cooperative competition with private-decentralized institutions and informal social control mechanisms. Below I will describe the case and reveal how cooperation is sustained.

\section{THE SPORT: ULTIMATE}

The Ultimate Players Association (UPA) is a thriving and exponentially growing North American organization of some 22,079 members (see Griggs 2009a for a discussion of Ultimate in the UK). ${ }^{4}$ In $2005,52,500$ members in 46 countries with World Flying Disc Federation (WFDF) membership associations were reported. In most major metropolitan areas around the world, Ultimate players organize into local Ultimate communities so as to develop and play the sport. Because of rapid growth and membership diversity, Ultimate competition is organized along two dimensions: level of competition and division. The first of which, level of competition, is divided into club, college, juniors, city league, and local pick-up. Competition is further divided within each level into divisions: masters, open (any gender or age can play), women's, and mixed. Within each division and level of competition (with the exception of pick-up) players organize into teams that generally travel across the country to compete. These competitions take the following form: two teams of seven players try to score goals on a field of play that is 40 yards wide and 120 yards long (including two 25-yard end zones on either end) by throwing and catching a plastic disc in an opponent's end zone, which results in one point for the attacking team. Ultimate is a transition game - running with the disc is a violation - in which players

\footnotetext{
${ }^{4}$ As of 2010 , the UPA changed their name to USA Ultimate.
} 
move from offense to defense when a disc is forced to the ground, contacts an out-ofbounds area, or is intercepted by a defensive player. Ultimate is also a non-contact sport where physical contact such as picks and screens are strictly prohibited. Foul violations, which are limitless, are identified, disputed, resolved, and retracted by the players, not by referees. Games are typically played to a point cap (first team to 15 wins) or an allotted time (hour and a half), whichever comes first. ${ }^{5}$

Although players might not know all of the rules (see Griggs 2011), a key characteristic of Ultimate is that those who play the sport also enforce the rules. Ultimate players refer to this system of self-governance, or ethos, as the spirit of the game (Robbins 2004). The spirit of the game constitutes the community's norms, ideals, and values - that honesty, integrity, and fairness is of equal value to winning. Since the governing bodies rarely supply third-party agents to monitor and sanction opportunism, this ethic of sportsmanship - a decentralized mechanism - is crucial for cooperation; making Ultimate an appropriate case to investigate the control capacity of informal social control in a large and spatially diffuse group.

I draw on participant observation, secondary organizational data, in-depth interviews, document analysis, and content analysis of the Usenet to study cooperation in Ultimate. From 2003 to 2005 I was a "complete" (Adler and Adler 1987) and "opportunistic" (Riemer 1977) member of a Pacific Northwest Open, Club team known as the Mallards (pseudonyms used throughout), attending most practices, tournaments (many of which were out of state), parties, and get-togethers. On average, I was totaling 10 hours of complete participation per week during the season (from March to October), compiling rich and detailed field notes. In total, for this study, I observed 16 tournaments and roughly 96 games of the Mallards. My field notes were supplemented by 22 semi-structured interviews lasting approximately 90 minutes each (Holstein and Gubrium 2002), and casual conversations with countless opponents, yielding roughly 3,000 pages of field notes and transcribed interviews. Data was also unobtrusively gathered from a recently published history book recounting the growth and development of the sport (Leonardo and Zagoria 2005), and the UPA's quarterly magazine titled Ultimate News, which was first published in 1980. All of this data is accompanied by content analysis of the Ultimate community's Usenet domain, an open access computer-mediated communication system of exchanged text-based messages with more than 10,000 posts per year from 2000 to 2005.

I now address the factors unique to the Ultimate community that stifle "win-at-allcosts" behavior and increase the likelihood of successful cooperative competition. The factors come from two sources: private-centralized and private-decentralized organizations and institutions (see Ingram and Clay 2000). While the private-centralized organizations coordinate competition, produce simple rules, and intervene in high-cost situations, the private-decentralized social control mechanisms largely promote cooperative competition via informal norms, monitoring and sanctioning, information exchange and reputations, and selection and simulation devices. The list of factors is derived from the data sources referenced above.

\footnotetext{
${ }^{5}$ For a greater understanding of the sport see the following websites: www.usaultimate.org and www.wfdf.org; also see Griggs (2009a, b, 2011), Leonardo and Zagoria (2005), Robbins (2004), and Thornton (1998).
} 


\section{PRIVATE-CENTRALIZED CONTROL}

In Ultimate, winning was the primary goal. While some players expressed how they enjoyed the "journey" or the "process" of working as a team to attain this goal, the engine of this journey, as noted by all those interviewed, was the desire to win. A Mallards player noted, "We don't spend countless hours of our time in physical and mental exhaustion to lose. We play this game to win." This desire to win can unfortunately result in individual opportunism, or the violation of the rules to increase the probability of winning. Yet if each player acted opportunistically, competition (i.e., the common good) would collapse, producing a collectively irrational outcome and the breakdown of competition. In other words, Ultimate players must cooperate in order to compete (Lüschen 1980; Nelson and Cody 1979), but face conflicting individual interests on their road to cooperation: the desire to win at the possible expense of following the rules on the one hand, and the desire to win while competing fairly on the other; the former of which yields the greatest individual benefit, all else being equal. Because of this dilemma, the Ultimate community faces four types of costs: (1) the costs of regulating team and player eligibility; (2) the costs of coordinating competition; (3) the costs of negotiating and bargaining foul violations; and (4) the costs of detecting and controlling malfeasance. Since the goal of this investigation is to understand cooperative competition, the primary focus of the remaining paper will be devoted to illustrating how the Ultimate community resolves costs three and four.

According to centralists, the Ultimate community's governing bodies - the WFDF and the UPA, for instance - should fully absorb all four of the costs outlined above. Although the organizations recognize that Ultimate players are subject to high costs, the size and geographic span of the Ultimate community, in addition to each respective organization's lack of resources and direct control, limits the realization of widespread organizational cost absorption. As a result, the various governing bodies have initiated measures that entirely manage the first costs, partially pay the costs of the second, and provide limited, if any, resources for the third and fourth costs. The measures that reduce costs two through four include coordinating competition, creating and maintaining simple rules of play, ${ }^{6}$ and intervening in competition only when the community's informal system of social control becomes ineffective at suppressing opportunism.

In short, Ultimate competitions are beset by the individual temptation to violate the rules, which is further exaggerated by the size and diffusion of the sport. Centralist theory contends that the various governing bodies should maintain

\footnotetext{
${ }^{6}$ The coordination of competition and maintenance of simple rules will not be explored in detail. I will, however, briefly describe the organizations' involvement in both. First, in Ultimate, the reduction of coordination costs by the WFDF and the UPA was reserved for premier events-Worlds for the WFDF and the Nationals series (club, college, and juniors) for the UPA. Besides these premier events, the UPA had minimal involvement in the coordination of tournaments that occurred from November to April (college) and from June to September (club). Even the National series (sectionals and regionals) was coordinated by players who were participating in the tournament and not by a representative from the UPA. The creation of teams and coordination of competition, as a result, was almost exclusively left to be absorbed or resolved by the players. Second, since simple rules can reduce the costs of conflict resolution, and, hence, contribute to collective action, the organizations had maintained a set of rules that were basic and clear enough for non-specialists (i.e,. the average Ultimate player) to understand and enforce. For a thorough review of the rules see the Official Rules of Ultimate: 11th Edition.
} 
cooperative competition in Ultimate. Yet, contrary to expectations, the role of these organizations is limited in control and scope. Instead, Ultimate players rely on private-decentralized institutions and informal social control mechanisms to suppress opportunism and promote cooperation. Learning more about how these informal systems of social control act alone and in concert with private-centralized organizations to reduce costs three and four above is crucial to understanding cooperative competition in Ultimate and a key contribution of this paper.

\title{
PRIVATE-DECENTRALIZED CONTROL
}

Despite the presence of the governing bodies, they played a limited role in alleviating problems of individual malfeasance during competition. One of the most surprising discoveries in Ultimate was the creativity and variety of informal social control mechanisms used by Open, Club players and teams to remedy opportunism. Below I will describe these structures with data, narrative, and findings that were abstracted during my tenure on the Mallards.

\section{Norms}

Defining the basic rules of the game simply and clearly can be thought of as a first step in promoting cooperation. In general, as rule complexity expands so too does individual ignorance of the rules. The issue is that this ignorance increases the costs of resolving conflict and makes cooperation more difficult to achieve (Hardin 1982). Yet the rules are simply a framework for play: what specifies a score, what establishes a violation, and how many players are allowed on the field at once. Norms in Ultimate, on the other hand, are "rules about following the rules." Ultimate norms identify permissible and unacceptable behavior that warrant graduated rewards and punishments; they specify what an individual ought to do, what behavioral standards they should abide by, and how to chastise or praise members who follow or violate the rules, respectively (see Coleman 1990). Below I will outline the norms and values unique to Ultimate in greater detail and buttress this with accounts and testimonies from Ultimate players.

Spirit of the game. The overarching system of norms, or ethos, that permeated all divisions and levels of competition, and painted Ultimate as a moral community, was the spirit of the game (SOTG). The official definition is as follows:

\begin{abstract}
Ultimate relies upon a spirit of sportsmanship which places the responsibility for fair play on the player. Highly competitive play is encouraged, but never at the expense of mutual respect among players, adherence to the agreed upon rules of the game, or the basic joy of play. Protection of these vital elements serves to eliminate adverse conduct from the Ultimate Field. Such actions as taunting of opposing players, dangerous aggression, belligerent intimidation, intentional fouling, or other "win-at-all-costs" behavior are contrary to the spirit of the game and must be avoided by all players. (Ultimate Players Association 2007, p. 2)
\end{abstract}

Although SOTG formally underscores responsibility, respect, and honesty, Mallard and non-Mallard players alike broadly outlined SOTG in their own words as 
"integrity ... if you did something wrong and you know it then you are responsible for saying that"; being "honest with yourself and honest with everybody around you"; "... respect for opponents, respect for the game, respect for the Ultimate community... not yelling and 'losing your head' with opponents"; and, assuming that "... nobody is out there to win-at-all-costs. I always presume the best of my opponent... once you start assuming that you can't trust 'spirit' it's strength will falter." While certain elements of SOTG might appear idealistic, a few players on the Mallards provided what they called a "stripped down version" of the ethos: "... making the right calls. Recognizing how fragile the game can be. Spirit is simply not being a cheater." Whereas other players said: "Everybody follows the rules, you don't cheat, and that's it" or, simply, " ... be fair." Regardless of the interpretation, most Ultimate players I interviewed or conversed with were verbally committed to SOTG. But even the few players that were not — one player from my field notes said that " . . . there isn't a 'spirit.' It's some stupid Hippy-thing that just means 'respect"'-recognized what SOTG represented and why elements of it were necessary and important.

In short, the SOTG was a system of welfare-maximizing norms (see Ellickson 1991) that allowed players to cooperatively compete, realize their collective welfare"quality and fluid games" (Jimmerson 1996; Robbins 2004) — and avoid "winning-atall-costs" behavior. What is interesting, however, was how SOTG had such a large scope regardless of Ultimate's size and spatial diffusion and in spite of Ellickson's (1991) assertion that informal social control, such as welfare-maximizing norms, will likely fail under such conditions.

Letting-it-slide. In Open, Club Ultimate, SOTG was modified by another norm that held that a player should let minor infractions "slide" if a foul was committed against an opponent without it being identified by that opponent. If this norm was enacted, the typical response to an isolated violation was a non-response. Players noted during interviews that if they received physical play they would "play through it and remember." That: "I will typically start out games by "testing the waters', so to speak, and see what is ok and what isn't." Rather than identify the infraction, complain about opportunism, or sanction the violation some other way, players would overtly ignore the malfeasance and remember the violation. However, once an infraction was identified by an opponent, a player who was of a "good" type would generally stop committing infractions, apologize, or acknowledge the transgression and commence play if and only if they were not transgressed against prior. Similar "live and let live" systems exist in countless social settings, ranging from swimming (Nixon 1986) and cycling (Albert 1991) to cattle ranching (Ellickson 1991) and lobster farming (Acheson 2003).

I continuously observed "letting-it-slide" during competitions and the following excerpt is just one of many from my field notes:

I had been watching these two players commit infractions against one another the entire game: one player would lightly grab the other's jersey or physically grab the other's arm while on the mark, while the other player would bump into the other player while he was cutting. Clearly both players were breaking the rules. Finally, at a pivotal moment toward the end of the game, one player decided to identify a violation. The opponent quickly responded out of frustration, "You're going to 
call that now? You've been hacking me the whole game too!" The other player quickly retracted his call.

"Letting-it-slide" may appear antithetical to the SOTG since it encouraged rule-breaking, while the SOTG espoused fair-play, respect, and diligently following the rules. But keep in mind that several conditions found in Open, Club Ultimate favored this "live and let live" system. First, the intentionality of infractions was difficult to discern and players assumed that opponents would make mistakes. If an opponent repeatedly violated the rules, this would alert the player that the opponent was playing opportunistically. Often players would identify foul violations only upon repeated infractions or if the infraction was egregious. Players realized that minor infractions were an inevitable part of the game, and chose to manage minor infractions not by identifying or sanctioning each violation, but by "keeping tabs." "You really do remember who screwed you, how often, and to what degree" Anderson said in a casual conversation after a game.

Second, most players did not expect strict tit-for-tat reciprocity, but rather a form of reciprocal restraint; that is, to both receive and to give infractions at some point. The advantage of the mutuality of violations was that each player was able to minimize stoppages of the game and avoid foul escalation without expending time or energy on resolving conflict. Only once infractions were continuously unreciprocated by the same opponent, rules were repeatedly violated to gain an advantage, or minor infractions were invoked in high cost situations (i.e., towards the end of games or tournaments) would players resort to sanctions. As I show later, severe transgressions such as egregious "win-at-all-costs" behavior or dangerous plays did occur, and in such instances graduated sanctions were employed.

Oughtness. SOTG was respected, and diligently followed, because players believed they ought to (Klosko 1987). They were motivated out of moral obligations and principles of fairness. An interview with Gary exemplified conversations and interviews I experienced: "I think I've realized more how unique calling our own violations is and how important it is that we do uphold the rules that we have on our own... I've seen how important it is to make the right calls... otherwise the game turns into a back and forth call fest." All of the interviewed players provided similar testimonies: that following SOTG was "the right thing to do" and "you just don't screw anybody else with bad calls." Edgar said, "I feel like I've made an effort to play fairly and, you know, openly to talk about what my problems are with other guys. If I think about it, nobody is out there to win-at-all-costs." Finally, an excerpt from an interview with the 2005 Farricker Spirit Award winner illustrates how SOTG exemplified personal ideals and standards:

2005 Winner: Personally, I enjoy playing well in a spirited way, while having a good time. After looking back at all the bad calls and arguments I've had over the years, and comparing them to the times I took back a bad call or talked to an opponent calmly, I've realized that the latter means so much more to me as a person than winning a game. (Mooney 2005, p. 24)

In short, Ultimate players abided by SOTG for reasons similar to those who contribute to the establishment of a public good or to those that partake in legal protests (Finkel et al. 1989): because they believe they should. 


\section{Monitoring and Sanctioning}

Central to theories of cooperation, and what gives informal norms their motivating power, are monitoring and sanctioning mechanisms. Collective action theorists view these mechanisms as classic solutions to social dilemmas and free-rider problems since they alter the costs and benefits of action and motivate players to behave pro-socially (e.g., Hechter 1987). To help explain cooperative competition in Ultimate, I will describe the various decentralized monitoring and sanctioning mechanisms by which most competition was controlled.

Between-team monitoring and sanctioning. Perfect monitoring in Ultimate was nested within an imperfect information system. As one player said, "We know everything but absolutely nothing." To elucidate, monitoring was absolute in every discrete game. Competitions, for example, pitted two teams most concerned with cheating in direct conflict with one another. Each team within a discrete game was familiar with all proceedings: who committed a foul, how often, at what severity, and under what conditions. The presence of one team often deterred the opponent from committing gross violations, and vise-versa. Because of the structure of competition in Ultimate neither team had to invest many resources in alternative monitoring devices. Monitoring, under such conditions, was a simple by-product of playing the game.

The mildest form of between-team sanctions were dyadic (i.e., player-toopponent) and social and psychological in nature. Players would first try letting violations slide. If that was unsuccessful, players simply notified the opponent of their infraction, such as: "Hey, come on man, let's just play." When milder measures like "letting-it-slide" or warnings failed, a player would overtly disapprove of an opponent's behavior. In an interview Jon stated: "I try not and engage too much. I'll throw a couple nasty remarks like 'you're being an asshole' when people start cheating but I don't keep it up. If I thought it would help I might. Deal with it. Ignore it. Play through it. Don't let it get to you is the message." Later, at an Ultimate tournament, I watched Jon point to an opponent and quietly tell him "you're an asshole" and quickly recommence play with the accused "backing off" and Jon never confronting the player again. Undoubtedly, as my field notes attest, the majority of sanctions in Open, Club Ultimate fell within these two categories: warnings and disapproval.

Yet dyadic punishments were occasionally not enough and other forms of "collective" incentives were used. When opponents frequently engaged in opportunism, opposing teams - to reduce the individual burden of sanctioning and to increase a sanction's effectiveness-would make comments to the offender, paralleling dyadic disapproval but at the aggregate level. My fieldnotes show that teams would yell from the sideline after a violation "are you serious" and "you're full of shit." A Mallards player stated after a game, "it makes it much harder to uphold your call if the entire opposition is screaming bloody murder." In a casual conversation, Devin stated the opposite: "I find that the ones who are the true cheaters are the ones where nothing you can say matters." If this was the case, team leadership would demand that the opposing team leadership rectify the situation either by controlling their teammate or by removing their teammate from play. The former was much more common than the latter as indicated by interviews and field notes. The 
Mallards, however, occasionally removed their own players from competition if they repeatedly taunted opponents. This transpired a handful of times and was consistently directed toward one teammate in particular. The sanction was effective and the threat of removal often caused him to change his behavior.

Within-team monitoring and sanctioning. In an effort to reduce disagreements, the Mallards instituted a conflict resolution mechanism that constrained and validated rule violations invoked by teammates. In an interview Arnold stated: "If I didn't get a good view of it I'll encourage my teammates who make controversial calls to listen to their teammates, say 'listen to your fellow Mallards.' That is a code we try and help everybody live by: when you're in the middle of a questionable call situation ask your teammates." Gary stated in an interview, "... check with your teammates before you give up a call or stick with your call. Often with reflection and checking with your teammates you can see the truth. I think everyone on our team respects the truth of what truly happened on a play." This style of "morality" play often garnered social and psychological rewards. Players who made calls in favor of opponents or hurt their respective team's chances of winning when they easily could have violated the rules received approval from opponents and the "crowd." These simply included kudos such as "nice call" or "good Spirit." According to my field notes, when this conflict resolution mechanism was used it generally resolved disagreements in a timely manner without much discussion.

Crowds. Besides between- and within-team enforcement, monitoring and sanctioning was undertaken, when available, by Ultimate "crowds" and spectators. These spectators were usually fellow Ultimate teams that failed to advance to the next round of tournament competition. "Crowds" did not typically emerge on the first day of tournaments, and would subsequently grow in size as the tournament progressed from quarterfinals to finals. "Crowds" were an incomplete monitoring mechanism, yet greatly contributed to sanctioning capacity and the development of reputations when available. With "crowds," not only was opportunism observed by opponents, but it was also witnessed by community members who would collectively disapprove of cheating. The following anecdote illustrates how "crowds" in Ultimate worked (interview):

I would site an example of this guy from the Squids, Trey, who is one of the people who I would say is a cheater. Who makes a lot of bad calls and who breaks the rules himself and argues when people call him on it. He misbehaved so badly in previous games during the UPA championship that during the finals the next day 20 or 30 people watching the game would scream "You suck!" or "You cheating fuck!" whenever he touched the disc. They screamed it over and over. $\mathrm{He}$ traveled a ton of times during the finals. It was insane. That's part of what he does. You bring bad ju-ju on yourself by manipulating the game. (Jon)

Federated control. I should note that although Ultimate players used decentralized forms of control to promote cooperative competition, they would respond to severe infractions by contacting organizational officials. These notifications typically occurred after all other decentralized methods had been exhausted. The governing bodies were intolerant of violence and would prohibit violent players from 
competing in organizationally sanctioned tournaments, which included the championship series. And contacting the governing bodies did produce results. While violent acts and subsequent expulsion by the UPA were not observed in the present study, violent players had been banned from competing in UPA sanctioned tournaments in the past. Besides these rare instances of organizational intervention, all other conflict was purely resolved, as already discussed, by Ultimate's informal system of social control.

As we have just seen above, most of this large, and expanding, self-governing community was organized into various tiers of competition and divisions; composed of horizontally managed micro-units (i.e., teams) such as the Mallards that monitored and sanctioned their own members. Under these conditions, monitoring and sanctioning was simply a byproduct of competition. As such, the community needed to expend very little resources on other forms of decentralized control. Of those resources, three will be explored below: face-to-face and computer-mediated gossip, reputations, and selection and simulation devices.

\section{Information Exchange}

Although monitoring was perfect within discrete games, it was imperfect outside of discrete games. The problem is that such conditions promote incomplete information and greater uncertainty, which facilitates opportunism and cheating. To alleviate this issue, Ultimate teams relied on two information sharing mechanisms (face-to-face and computer mediated gossip) and one signaling mechanism (reputations).

Face-to-face gossip. Players used face-to-face gossip to exchange information on "how games had gone," "anything out of the ordinary like taking a call back under weird circumstances," or who "cheated to win," "played aggressively," or "were assholes." Gossip, in this case, concurrently exchanged much needed information and sanctioned those who either followed or violated the rules. Once exchanged, players would relay this information to their respective teams. This form of exchange typically occurred during tournaments. An excerpt from my field notes illustrates how this was done:
Long after our last game and during our bi Steve returns from hanging out with an old college teammate who now plays for Anodyn (team pseudonym). $\mathrm{He}$ recounts a funny story of them in college and proceeds to tell us how their games went, specifically the MUD game. He said one player in particular [name removed] blatantly cheated and admitted to it after the game was finished. One of our captains proceeded to remind us of how to manage cheating and to always just "laugh it off."

The Usenet. The Ultimate community also relied on a Usenet domain to enhance information exchange. The domain was primarily used by the players to coordinate tournaments and pick-up games, to negotiate ethical standards of play, to discuss field equipment, and to relay tournament results. Besides scores and spectacular plays, this latter process also included warnings and caveats about other teams and players and generally assumed the following form: players witness to 
cheating or exceptionally spirited play posted such observations on the Usenet domain where others in the Ultimate community would share this information with their respective teammates. The following excerpt illustrates how the Usenet was utilized to identify and discuss opportunism:

11.7.05, 7:52 p.m.: Can we expect an apology for Jared being a blatant and obvious cheater? Doesn't matter that neither Polar nor any Observer noticed. I did. Others did. The open div reporter did, too. (Cynic1)

11.7.05, 8:44 p.m.: ... I saw this shit! I saw this shit! It was bogus! Jared called a foul. A foul on a defensive attempt. A foul he unscrupulously rescinded when he saw the receiver throw it away immediately. He fucking cheated! He fucking cheated!... You might think you'd get away with a bad call, or a slight travel, or a hack. But what hubris leads you to think you're going to call a foul with hundreds of spectators around witnessing you and then allow you to fucking cheat? (Cynic2)

Jared then later responded:

11.8.05, 12:03 a.m.: Rather than apologizing for my actions, I'll simply explain what happened and await your response. I went up for the disc and called strip (not foul). The errant disc made its way into another Polar player's hand. He quickly turfed it. My thought when the disc hit the ground was to play. I knew that if anyone involved in the play had wanted to, they could have stopped play and the call could have been revisited. That's how things work in Ultimate. (Jared)

Reputations. Those players that made the "right" decisions, and did not cheat or "bend" the rules in situations costly to their team, acquired "good" reputations. Cam stated in an interview that "good" type actions were "making the right decision at a detrimental time for you as a player in the game where it is easy to get away with it." Gary recalled in an informal conversation: "Those people that you consider to be the highest tier of honor are the kind of people you can ask 'was this the right call, did I make the wrong call, did you make the wrong call?' And you can expect them to be honorable and make the right decision." "Good" reputations also developed when players sanctioned themselves and their teammates openly during competition. During an interview Jon stated, "I think [good] reputations are attained when a person makes the decision to admit that they're wrong and they understand that they're wrong or is willing to make a call or a case against they're team when they believe it is fair and the right thing to do. I think it is attained through often times making the right call or the fair call and calling it as you truly see it even when it hurts your team."

On the other hand, "bad" reputations emerged by playing reckless, disregarding the safety of others, berating opponents, and cheating to gain an advantage. There were, however, two methods for building poor reputations other than recklessness and unsafe conduct: opportunism in high cost situations for the opponent and the frequency and consistency of dubious rule violations. Devin stated that "bad" reputations emerged when "... they make bad calls, it's the way they argue their calls, it's, you know, the time that they make their calls at the end of a game for 
example. There is any number of ways that they can acquire this reputation. It's the importance of the game in which it happens." Cheating had direct and indirect consequences. In the short-term, it provided the opportunistic team with a direct advantage. In the long-term, transgressions were remembered, resulting in untrustworthy players and teams not given the benefit of the doubt and suffering future transgressions without revocations. A Mallards player revealed that "I've made some bad calls and guys have called me on it. They tell me that I've screwed them in the past so they're just getting back at me." In short, reputations prepared teams for possible civility or misconduct, allowing them to adjust their strategies accordingly and plan ahead.

\section{Selection and Simulation}

Besides norms and other informal devices of social control, groups often employ selection and simulation mechanisms in the hopes of creating a community of self-disciplined actors that voluntarily commit to shared standards (Gorski 2003; Kanter 1972). These mechanisms are particularly important because they reduce uncertainty during social interaction and save on the costs of social control (Kiser and Baer 2005). In relation to the Ultimate community, various selection and simulation mechanisms, both individual and collective, were found to help maintain cooperative competition. Below, I will review these in greater detail.

Individual self-selection. The various data sources revealed that Open, Club Ultimate players chose to play Ultimate based on their personal dispositions and preferences. During interviews, players invoked a range of reasons for playing the sport: "I was unsuccessful at my other sports and needed a competitive outlet," "... the fringe, iconoclastic nature of Ultimate I enjoyed," "I really liked the community feel to the sport," "the disc is a neat object to build a sport around," and "I liked how the games were controlled by the players." While diverse, the common response among those interviewed was the latter: all of the Mallards players identified either SOTG or idealizations of self-regulation as a draw to the sport. As one player noted (interview):

People like Ultimate because of how it is exactly not other sports. It's not basketball. It's not football. It's not soccer. I was an ok athlete in my other sports. I wasn't the greatest runner but I always was good at Ultimate. The people were fun and I liked the crazy ways you could throw the disc. It's just like when people realize they're not good at math and decide to be an English teacher. People's temperaments lead them to do different things. Personally, I like activities where people resolve conflict themselves. (Gavin)

Similar testaments were found on the Usenet.

1.17.02, 5:22 p.m.: I mean, I've seen some pretty athleticly [sic] talented people playing ultimate because they were sick of their old sport. If someone wants to play basketball, they'll play basketball. If someone wants to play ultimate, they'll play ultimate. When I found out ultimate was played without referees, I was 
admittedly a little confused, but not deterred, and it seems neither were you. (anonymous1)

Group social selection. Players individually chose to play Ultimate for numerous reasons, but more often than not they selected the sport because of its communitarian roots. This self-selection mechanism, however, did not always select self-disciplined players willing to abide by SOTG. Sometimes this mechanism attracted players who were simply interested in Ultimate as a competitive outlet and cared less for its system of self-governance. To minimize the negative impact of these players on the "quality and flow" of the game, Ultimate teams would select teammates who not only exhibited proficient athletic skills, capable throwing ability, and instinctive field sense, but who also demonstrated the capacity to follow the rules, abide by SOTG, and let minor rule infractions "slide"; or, conversely, excluded players with "bad" reputations, barring them from future competitions.

The Mallards accomplished this by annually nominating a group of individuals, called the "personnel committee," who would determine the team's roster for the forthcoming season. Although the Mallards rarely encountered players who they excluded from the team because of a "bad" reputation or consistently poor sportsmanship, instances of this did occur. The following excerpt illustrates the group selection process. In the spring of 2003 the personnel committee decided not to allow a player on the team for having a "bad" reputation (field notes):

Cart: Next agenda, or person, to talk about is taking Art or not?

Devin: [lightly laughs] I heard he's a nightmare. I've only heard bad things about him. He's burned so many bridges. He's a cancer and a bad teammate. I don't think he listens well to team leadership. Do you think he'll listen to you Cal?

Cal: [shakes his head and shrugs his shoulders in an unconvincing manner].

Devin: Arnold made that statement earlier about how our team has wonderful team chemistry. I don't think Art is gonna help at all.

Cal: Well, I did talk to some of his older teammates. They didn't mention anything about chemistry, but they did say that he doesn't follow the system or the rules.

Arnold: We should really look at the cost/benefits with Art. Does what he brings outweigh the costs? In my opinion, Art's costs outweigh the benefits. He's just going to bring us down. We'll also have to apologize for him.

This selection process not only applied to new "tryouts," but to returning Mallards players as well. Although the latter was unobserved, numerous veteran players recounted how "cutting" returning players for poor sportsmanship had occurred in the past. According to these accounts, there was a player in the mid-1990s that "pushed the limits of the rules" and would either cheat outright, play overly physical, or verbally berate opponents. This led to the player developing a "bad" reputation along with the Mallards via association. Many Mallards players did not want to be perceived as such a team and called for a meeting. After a long debate in which one teammate stated I would "... rather eat a shit sandwich than play with him again", this player was asked to leave the team for "... his historic 
assholemanship." Interestingly, after his removal, he was courted by another team that taught him how to play "spiritedly," and, as noted by a Mallards player, "... improved significantly. He's now tolerable to play against."

Simulation. Individual and group selection mechanisms factored heavily in the creation of Ultimate as a self-disciplined community of competitors. This self-discipline, however, was not just about players choosing Ultimate because they identified with its system of self-governance or because they were excluded from competition, it was also about rigorous simulation that involved the reproduction of competition through practice. In other words, simulation and practice was an artificial replication of inter-team competition that unintentionally facilitated the adoption of Ultimate specific norms and values.

To provide some context, the Mallards practiced and scrimmaged to first and foremost increase efficiency and effectiveness at tournaments. Usually, as a team, the Mallards participated in eight tournaments (six games a tournament on average) a season (June to the end of October). For the remaining time between June and the end of October, the Mallards practiced roughly four days a week. During this period, the team would incorporate new techniques and strategies and participate in various drills. The intended result of these simulations was to create a sense of solidarity and esprit de corps among the players and to refine their skills and abilities; the unintended result was the continuous monitoring and sanctioning of those who failed to abide by the rules and SOTG. Repeated simulations and drilling not only increased the skill proficiency of the players it also taught them how to be members of a community with a certain value-rational system.

\section{DISCUSSION AND CONCLUSION}

This study examines the various mechanisms that promote cooperation under theoretical conditions considered inadequate for informal social control. I have illustrated that social order in Ultimate is largely driven by private-decentralized sources and not by third-party agents, and that personal ideals, standards, and scruples of individual players are critical for overcoming social dilemmas in the sport. The evidence suggests that the classic bifurcation between decentralized and centralized social control based simply on group size and spatial diffusion should be reconsidered. Below I will briefly summarize the findings, address drawbacks of the study, illustrate the wider significance of the results, and offer avenues for future research.

The results show that Ultimate is embedded within tiers of organizational constraint and is federally managed. Although Ultimate teams are controlled by various governing bodies that create simple rules and coordinate some activities, teams largely oversee and govern their own members and the members of others during competition. This greatly reduces monitoring and sanctioning costs facing the Ultimate community and limits the intervention of the governing bodies to severe and costly transgressions. It is in this sense that the governing bodies operate: as distally constraining and locally enabling centralized organizations that intercede only under conditions of high risk or cost for the players. 
As such, centralized organizations play a limited role in the everyday competitions found in Ultimate. Instead of relying exclusively on the governing bodies to promote cooperation, players depend on an informal system of social control. Central to this system is an ethos known as the spirit of the game in which honesty and integrity are paramount and eye-for-an-eye reciprocity is shunned in favor of letting infractions slide so as to keep a continual "flow" of the game. Interestingly, the ethos is supported by a perfect, yet flawed, monitoring system: information is perfect within competitions, but imperfect outside of competitions. As a result, players rely on a variety of mechanisms to increase monitoring capacity and the possibility of sanctions, which include within- and between-team observations, "crowd," wordof-mouth exchange, and computer-mediated communication. Sanctions within the community are wide-ranging and can originate from various sources, much like the community's monitoring mechanisms.

The Ultimate community's collection of compliance mechanisms and norms provide the basis for cooperation, although part of the explanation hinges on reputations. Since uncertainty pervades the community, players and teams develop "good" and "bad" reputations. If players and teams frequently disregard the rules, the norms, or the sanctions under high cost conditions, reputations develop that allow opposing teams to adjust their strategies accordingly, and prepare for possible civility or misconduct. By developing reputations, teams are better able to select-in and selectout players with "good" and "bad" reputations, respectively, and promote a selfdisciplined community willing to abide by certain moral standards. And if the group selection mechanisms are unsuccessful, players learn through repeated simulation and practice how to follow the norms and values unique to Ultimate.

Yet these mechanisms of informal social control are not simply constraints that alter the costs and benefits of action in order to facilitate pro-social behavior. These institutions and devices reflect the community's values and are present not because the community fears rampant opportunism, but because players are acutely aware of the temptation to defect among the few and the consequences of malfeasance. Ultimate players are driven by reasons and principles: about what type of player they should be, how they should play the game, and their idealizations of what the game means. The various organizations, the spirit of the game, the types of monitoring and sanctioning mechanisms, the federal system of control, and reputations all matter; but foundational are the ideals and standards each player sets for himself or herself. Thus, while the entirety of the Ultimate community constitutes cell 4 in Table 1, the sport is organized to fill cells 1 through 3 so as to adequately enforce the rules and circumvent third-party control.

While ideas of cooperation and competition are ubiquitous in sociology, economics, and political science, the findings here are closely analogous to classic ideas found in the sociology of sport literature (Coakley 2004; Eitzen 1999). One of the more compelling and unique elements of amateur sport is not that cooperation is achieved in the face of competition, but that cooperation and competition mutually depend on and reinforce the other (e.g., Nelson and Cody 1979). In a sense, it is impossible to disentangle cooperation from competition and competition from cooperation; players must cooperate in order to compete, and without cooperation, competition quickly dissolves into conflict, leading to problems of social order. In other words, cooperative competition is what Hechter (1987) calls corporate 
obligations and mutual dependence. The results suggest that Ultimate players are aware of this dialectic and use numerous informal social control mechanisms to keep the symbiotic relationship between cooperation and competition in tact and to promote what Nelson and Cody (1979) call "fairplay." It is thus reasonable to expect that without "fairplay" a rift between cooperation and competition would emerge, sending Ultimate into a vicious cycle of mutual distrust and collective inaction.

Although my observations provide an empirical example of decentralized cooperation under theoretically precarious conditions, the study suffers from an obvious limitation. My observations include a small portion of the Ultimate community. The majority of my interviews and field-notes were abstracted from one highly successful team (the Mallards) within one level of competition (Club) and one division (Open). Although I witnessed many competitions and conversed with multiple opponents within the Open, Club circuit, my data was mainly informed by my interactions with the Mallards. This obviously limits generalizability of the findings. Do women's teams or mixed teams follow SOTG more strictly or leniently than Open, Club Ultimate teams? Have juniors' players adopted the strategy of "letting-it-slide"? Would observing a less successful team alter my findings? Further research on Ultimate should study different levels of competition and divisions in order to compare and contrast the differential structural processes found in the Ultimate community. Doing so would contribute to our understanding of the conditions that foster certain forms of informal social control.

Despite limitations and drawbacks, the study offers an empirical insight into cooperation among a large and spatially diffuse group. But if group size and spatial diffusion is not the engine for the emergence of a centralized third-party agent, then what is? The answer may be found with declines in monitoring and sanctioning (Hechter 1987). The Ultimate community overcame the group size and spatial diffusion effects while maintaining adequate monitoring and sanctioning capacity. Typically, as group size and spatiality increases, monitoring and sanctioning capacity decreases and, as a result, third-party agents become necessary to promote cooperation in spite of mutual dependence and corporate obligations found in groups (see Hechter 1987). But the widespread implementation of referees in Ultimate has not yet occurred. This is possibly because Ultimate competitions only require contributions from 14 individuals. If, on the other hand, Ultimate required all 20,000 UPA members instead of only 14 players in order to compete, informal cooperation would be extremely tenuous; possibly spurring the creation of a refereed system that secured cooperative competition.

In conclusion, the present article examines the scope and applicability of private-centralized and private-decentralized systems of social control. The article's contributions are largely empirical. It outlines the mechanisms that lead to cooperation under conditions highly conducive to social dilemmas. The results suggest that the scope of decentralized control is greater than previously thought. The effect, however, is conditional on the limited presence of centralized organizations that encourage the development and reproduction of local enforcement. Such findings imply that centralists only considering group size and geographic divisions may produce faulty predictions for the necessity of organizations or third-party agents to overcome all collective action issues. The research highlights the classic 
sociological insight that norms and values matter even under theoretically precarious conditions. For this reason, studying the conditions responsible for the emergence of oughtness, and analytically modeling its production while considering the instrumentality of norms, is a primary and obviously difficult task for future research.

\section{AUTHOR NOTE}

Blaine G. Robbins is a PhD candidate in the Department of Sociology at the University of Washington. His main research and teaching areas include social psychology, group processes, political sociology, and institutional analysis with an emphasis on particularized and generalized trust. He has published articles in International Political Science Review, Journal of Sport and Social Issues, Rationality and Society, and Social Indicators Research. He is currently working on his dissertation, which explores the relationship between institutional incentives and trust with factorial surveys.

\section{REFERENCES}

Acheson, James. 2003. Capturing the Commons: Devising Institutions to Manage the Maine Lobster Industry. Hanover, ME: University Press of New England.

Adler, Patricia and Peter Adler. 1987. Membership Roles in Field Research. Newbury Park, CA: Sage.

Albert, Edward. 1991. "Riding a Line: Competition and Cooperation in the Sport of Bicycle Racing." Sociology of Sport Journal 8:341-361.

Axelrod, Robert. 1984. The Evolution of Cooperation. New York: Basic Books.

Bendor, Jonathan and Dilip Mookherjee. 1987. "Institutional Structure and the Logic of Ongoing Collective Action." American Political Science Review 81:129-154.

Coakley, Jay. 2004. Sports in Society: Issues \& Controversies, 8th edition. Boston: McGraw-Hill.

Coleman, James. 1990. Foundations of Social Theory. Cambridge, MA: Harvard University Press.

Dixit, Avinash. 2004. Lawlessness and Economics, Alternative Modes of Governance. Oxford, UK: Oxford University Press.

Durkheim, Emile. [1893]1984. The Division of Labor in Society. London: MacMillan.

Eitzen, D. Stanley. 1999. Fair and Foul: Beyond the Myths and Paradoxes of Sport. Lanham, MD: Rowman \& Littlefield.

Ellickson, Robert. 1989. "A Hypothesis of Wealth-Maximizing Norms: Evidence from the Whaling Industry." Journal of Law, Economics, and Organization 5:83-97. 1991. Order Without Law. Cambridge, MA: Harvard University Press.

Finkel, Steven, Edward Muller, and Karl-Dieter Opp. 1989. "Personal Influence, Collective Rationality, and Mass Political Action.” American Political Science Review 83:885-903.

Fox, John and Melvin Guyer. 1978. " 'Public' Choice and Cooperation in N-Person Prisoner's Dilemma." Journal of Conflict Resolution 22:469-481.

Geertz, Clifford. 1978. "The Bazaar Economy: Information and Search in Peasant Marketing." The American Economic Review 68:28-32.

Gorski, Philip S. 2003. The Disciplinary Revolution: Calvinism and the Rise of the State in Early Modern Europe. Chicago: University of Chicago Press.

Greif, Avner. 1989. "Reputation and Coalitions in Medieval Trade: Evidence on the Maghribi Traders." Journal of Economic History 49:857-882. 
Griggs, Gerald. 2009a. "The Origins and Development of Ultimate Frisbee in the UK: From Creation to Recognition." The Sport Journal 12:3. . 2009b. "'Just a Sport Made Up in a Car Park': The Soft Landscape of Ultimate Frisbee." Social and Cultural Geography 10:757-70.

- 2011. "This Must Be the Only Sport in the World Where Most of the Players Don't Know the Rules': Operationalising Self Refereeing in UK Ultimate Frisbee." Sport in Society 14:97-110.

Hardin, Russell. 1982. Collective Action. Baltimore: The John Hopkins University Press.

Hechter, Michael. 1987. Principles of Group Solidarity. Berkeley: University of California Press. Hobbes, Thomas. [1651]1968. Leviathan. London: Penguin.

Holstein, James and Jaber Gubrium. 2002. "Active Interviewing." Pp. 112-126 in Qualitative Research Methods, edited by D. Weinberg. Boston: Blackwell.

Ingram, Paul and Karen Clay. 2000. "The Choice-Within-Constraints New Institutionalism and Implications for Sociology." Annual Review of Sociology 26:525-546.

Jerdee, Thomas and Benson Rosen. 1974. "Effects of Opportunity to Communicate and Visibility of Individual Decisions on Behavior in the Common Interest." Journal of Applied Social Psychology 59:712-716.

Jimerson, Jason. 1996. "Good Times \& Good Games: How Pickup Basketball Players use Wealth-Maximizing Norms." Journal of Contemporary Ethnography 25:353-371.

Kanter, Rosabeth Moss. 1972. Commitment and Community: Communes and Utopias in Sociological Perspective. Cambridge, MA: Harvard University Press.

Kiser, Edgar and Justin Baer. 2005. "The Bureaucratization of States: Toward an Analytical Weberianism.” Pp. 225-248 in Remaking Modernity: Politics, History, and Sociology, edited by Julia Adams, Elizabeth Clemens and Ann Shola Orloff. Durham, NC: Duke University Press.

Klosko, George. 1987. "The Principle of Fairness and Political Obligation." Ethics 97:353-362.

Kollock, Peter. 1998. "Social Dilemmas: The Anatomy of Cooperation." Annual Review of Sociology 24:183-214.

Landa, Janet T. 1981. "A Theory of the Ethnically Homogeneous Middleman Group: An Institutional Alternative to Contract Law." The Journal of Legal Studies 10:349-62.

Leonardo, Pasquale and Adam Zagoria. 2005. Ultimate: The First Four Decades. South Korea: Daehan Printing.

Lüschen, Günther. 1980. "Sociology of Sport: Development, Present State, and Prospects." Annual Review of Sociology 6:315-347.

McLaughlin, Thomas. 2008. Give and Go: Basketball as a Cultural Practice. New York: State University of New York Press.

Mooney, Steve. 2005, Winter. "Spirit of the Game." Ultimate News 25:24.

Nelson, Katherine and Carolyn Cody. 1979. "Competition, Cooperation, and Fair Play." International Review for the Sociology of Sport 14:97-104.

Nixon, Howard. 1986. "Social Order in a Leisure Setting: The Case of Recreational Swimmers in a Pool." Sociology of Sport Journal 3:320-332.

North, Douglas. 1990. Institutions, Institutional Change and Economic Performance. New York: Cambridge University Press.

Oliver, Pamela and Gerald Marwell. 1988. "The Paradox of Group Size in Collective Action: A Theory of the Critical Mass. II." American Sociological Review 53:1-8.

Olson, Mancur. 1965. The Logic of Collective Action. Cambridge, MA: Harvard University Press.

Ostrom, Elinor. 1990. Governing the Commons. New York: Cambridge University Press.

Ostrom, Elinor, James Walker, and Roy Gardner. 1992. "Covenants with and without a Sword: Self-Governance is Possible." American Political Science Review 86:404-417.

Riemer, Jeffrey. 1977. "Varieties of Opportunistic Research.” Urban Life 5:467-477. 
Robbins, Blaine. 2004. " 'That's Cheap.' The Rational Invocation of Norms, Practices, and an Ethos in Ultimate Frisbee." Journal of Sport \& Social Issues 28:314-337.

Simon, Herbert. 1969. The Science of the Artificial. Cambridge: Massachusetts Institute of Technology.

Taylor, Michael. 1976. Anarchy and Cooperation. Cambridge, UK: Cambridge University Press. Thornton, Andrew. 1998. "Ultimate Masculinities: An Ethnography of Power and Social Difference in Sport." Unpublished doctoral dissertation, University of Toronto, Toronto, Canada.

Ultimate Players Association. 2007. Official Rules of Ultimate, 11th edition. Boulder, CO: Ultimate Players Association.

Weber, Max. 1978. Economy and Society. Berkeley: University of California Press.

Williamson, Oliver. 1985. The Economic Institutions of Capitalism. New York: Free Press. 